\title{
Editorial
}

Justus Haucap*

\section{Wirtschaftspolitik jenseits der Corona-Krise}

https://doi.org/10.1515/pwp-2020-0012

Liebe Leserin, lieber Leser,

die Corona-Krise hat Europa und den Rest der Welt fest im Griff, viele andere Dinge rücken aktuell in den Hintergrund. Gleichwohl ist das vorliegende Heft „Corona-frei“: Niemand von den Autorinnen und Autoren befasst sich mit den ökonomischen Konsequenzen der Corona-Pandemie oder den wirtschaftspolitischen Maßnahmen, die sinnvoll wären, um den negativen wirtschaftlichen und sozialen Folgen der Corona-Krise entgegenzuwirken. Wir haben uns dafür entschieden, weil die Entwicklung heute, zum Zeitpunkt der editorischen Arbeiten an diesem Heft, noch außerordentlich dynamisch ist, was jede aktuelle Analyse und Einschätzung schnell veralten ließe. Im weiteren Jahresverlauf werden Sie dann aber auch bei uns Beiträge zu den Konsequenzen und Herausforderungen der CoronaKrise lesen können.

Die beiden Abbildungen in der Rubrik Unsere Welt in Zahlen illustrieren diesmal eine andere Herausforderung Europas: die digitale Ökonomie. Die erste Abbildung hat Holger Schmidt (Darmstadt) entwickelt; sie wird regelmäßig unter www.netzoekonom.de/plattform-oekonomie/ aktualisiert. Dargestellt sind die 100 wertvollsten Plattformen der Welt (Stand: 29. Februar 2020). Die Herausforderung für Europa wird schnell sichtbar: Von den 100 wertvollsten Plattformen sind lediglich 16 in Europa zu finden, ihr wertmäßiger Anteil beträgt sogar nur 3 Prozent. Amerika und Asien dominieren dagegen die Plattformökonomie. Inzwischen hat die Grafik eine so große Popularität erreicht, dass selbst die Europäische Kommission sie in ihren Publikationen verwendet. Die zweite Abbildung veranschaulicht, dass sich an der Dominanz amerikanischer und asiatischer Digitalunternehmen wohl auch so schnell nichts ändern wird. Von den 452 Startup-Unternehmen mit einer Bewertung von mehr als einer Milliarde Dollar befinden sich nur 12 in Deutschland, das sind noch nicht einmal 3 Prozent. Der ganz überwiegende Teil davon ist in den Vereinigten Staaten und in China beheimatet. Es besteht in

*Kontaktperson: Justus Haucap, Düsseldorf Institute for Competition Economics (DICE), Heinrich-Heine-Universität Düsseldorf, Universitätsstr.1, 40225 Düsseldorf, E-Mail: haucap@dice.hhu.de

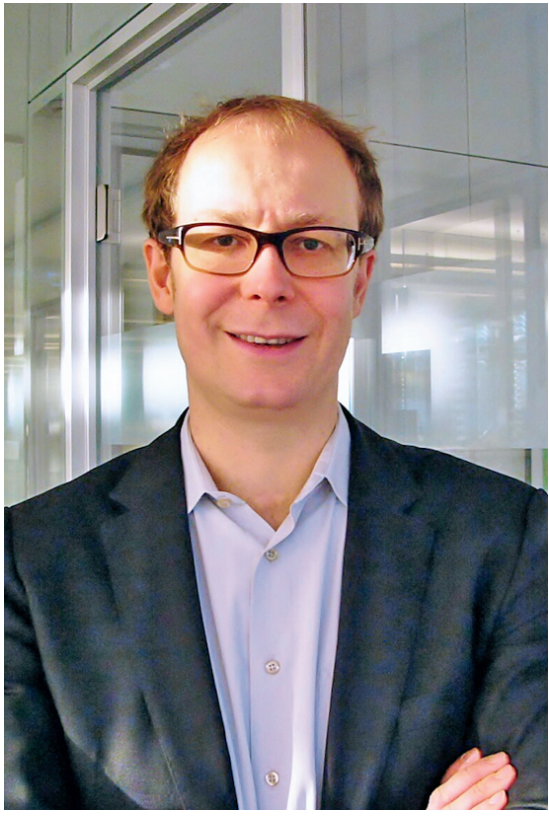

Europa offenbar dringend wirtschaftspolitischer Handlungsbedarf.

Selbst wenn in der derzeitigen Lage unser Augenmerk vor allem dem Corona-Virus gilt, gibt es doch auch etliche andere Themen, die aktuell von großer Bedeutung sind. In der Rubrik Aus aktuellem Anlass finden sich deshalb gleich drei Beiträge. Ottmar Edenhofer (PIK Potsdam), Matthias Kalkuhl (MCC Berlin) und Axel Ockenfels (Köln) argumentieren in ihrem Beitrag zum Klimaschutzprogramm der Bundesregierung, dass das Klimaschutzgesetz einen Paradigmenwechsel eingeleitet habe: den Einstieg in eine $\mathrm{CO}_{2}{ }^{-}$ Bepreisung als Leitinstrument der Klimapolitik. Damit werde die Tür für eine Stärkung der europäischen und internationalen Kooperation geöffnet. Dazu sei aber neben der europäischen auch die globale Klimapolitik neu auszurichten. Auch dort sollten sich die Verhandlungen auf $\mathrm{CO}_{2}$-Preise statt auf nationale Mengenziele konzentrieren. Die erforderliche Kooperation werde möglich, wenn die Regierungen Transferzahlungen strategisch und reziprok nutzten. So könne die Effektivität der Klimapolitik erhöht werden und zugleich ließen sich Verteilungskonflikte entschärfen.

Katja Greer (Monopolkommission) und Achim Wambach (ZEW Mannheim) untersuchen das Gesetz für einen fairen Kassenwettbewerb und bewerten es als einen von 
vielen kleinen Schritten zu mehr Wettbewerb auf dem Krankenkassenmarkt. Für eine umfassende Grundlage eines wirksamen Wettbewerbs in der GKV bedürfe es jedoch weiterer Reformen.

Andreas Knabe (Magdeburg), Ronnie Schöb (FU Berlin) und Marcel Thum (Dresden) schließlich kommentieren den von Oliver Bruttel, Arne Baumann und Matthias Dütsch verfassten Beitrag über die Beschäftigungseffekte des gesetzlichen Mindestlohns aus Heft 3/2019. In ihrem Beitrag hatten Bruttel et al. argumentiert, dass sich die sehr negativen Prognosen zur Beschäftigungswirkung der Einführung des Mindestlohns in Deutschland nicht bewahrheitet hätten. Knabe et al. halten dem entgegen, dass sich Prognosen und tatsächliche Beschäftigungswirkungen des Mindestlohns gar nicht wesentlich unterschieden. Zum einen hätten sich die Beschäftigungsverluste stark in einer Reduktion der Arbeitsstunden je Beschäftigten niedergeschlagen. Zum anderen erhielten weiterhin viele Arbeitnehmer weniger als den Mindestlohn, was die bislang messbaren negativen Beschäftigungswirkungen mindere.

In der Rubrik Wissenschaft im Überblick beschreibt Peter Zweifel die Entwicklung in der Gesundheitsökonomik anhand von Antworten auf fünf Fragen: Ist das Gut „Gesundheit“ anders als alle anderen Güter? Geht es in dem Fach zentral um die „Kostenexplosion“? Was ist die Bedeutung des moralischen Risikos im Vergleich zur adversen Selektion auf Märkten für Krankenversicherung mit Wettbewerb? Wie bedeutsam ist die anbieterinduzierte Nachfrage? Und gibt es eine Begründung für den außerordentlich hohen Grad an Regulierung im Gesundheitswesen?

In der Heftmitte findet sich wie üblich unser Gespräch. Karen Horn hat sich mit Heinz Rieter (Hamburg) über die Geschichte der Wirtschaftswissenschaften und ihren akademischen Nutzen, die Vorläufigkeit ökonomischer Erkenntnisse und das Verhältnis zwischen Wissenschaft, Politik und Recht unterhalten.

Es folgen drei Beiträge aus der Forschung. Den Auftakt machen Heinz Gebhardt (Mülheim) und Lars-Hinrich Siemers (Siegen) mit einer Analyse der Konsolidierungsfortschritte in den Länderfinanzen. Die „strukturelle“ Besserung sei wesentlich dem historisch niedrigen Zinsniveau zu verdanken und damit zum Teil nur temporärer Natur. Um die nachhaltigen Konsolidierungsfortschritte zu ermit- teln, haben die Autoren die Länderfinanzen daher nicht nur um konjunkturelle Einflüsse, sondern auch um die nur vorübergehenden Einsparungen im Schuldendienst bereinigt. Sie berechnen drei auf unterschiedlichen Annahmen zum nachhaltigen Zinsniveau basierende Szenarien und zeigen, dass 2017 nicht 14, sondern - je nach Szenario nur acht bis zehn Länder einen strukturell mindestens ausgeglichenen Haushalt erzielten. Die verbleibenden Länder wiesen teilweise hohe strukturelle Fehlbeträge auf, so dass bei ihnen weiterhin Konsolidierungsbedarf bestehe.

Johannes Kasinger, Lukas Nöh und Alfons Weichenrieder (alle Frankfurt) befassen sich ebenfalls mit den Auswirkungen des derzeitig niedrigen Zinsniveaus auf die Länderfinanzen. Die Autoren nehmen die Debatte um Zinsswaps in Hessen zum Anlass, die Fristigkeitsstruktur der Staatsschulden sowie den Einsatz von langfristigen Zinsswaps zu erörtern. Im Gegensatz zu einem privaten Bauherrn wirtschafte der Staat nicht für sich, sondern sei Sachwalter der Steuerzahler. Seinen Zinserhöhungsrisiken stünden Zinserhöhungschancen der Steuerzahler in deren Funktion als Kreditgeber gegenüber. Letzteres schwäche das Argument für langfristige Verschuldung, sei es durch langfristige Anleihen oder mit Finanzderivaten. Grundsätzlich könne eine Glättung der Zinslast allerdings helfen, die für den Schuldendienst notwendigen Steuern ebenfalls zu glätten und die Zusatzlast der Besteuerung zu mindern

Rainer Eppel und Helmut Mahringer (beide WIFO Wien) schließlich beleuchten die Chancen und Risiken unterschiedlicher Gestaltungsvarianten eines „Experience Rating" in der Arbeitslosenversicherung. Hintergrund ist der Befund, dass eine durch pauschale Arbeitgeberbeiträge finanzierte Arbeitslosenversicherung unerwünschte Umverteilungseffekte produziert und Anreize zu vermehrten, häufig nur vorübergehenden Beschäftigungsbeendigungen setzt. Studien zeigen für die Vereinigten Staaten, Kanada und einige europäische Staaten, dass dies einen substanziellen Teil der Arbeitslosigkeit verursacht.

Wie immer wünsche ich Ihnen Spaß und den ein oder anderen Erkenntnisgewinn beim Lesen. Für Ihr Feedback bin ich jederzeit dankbar.

Justus Haucap

Twitter: @PerspektivenWP 